\title{
Difficulties in the diagnosis and management of unsuspected tuberculous enteritis and colitis
}

\author{
E. J. MORAN CAMPBELL \\ From the Medical Unit, the Middlesex Hospital, London
}

SYNOPSIS Five patients with tuberculous enteritis and one with possible tuberculous colitis are described, all of whom presented difficult problems of diagnosis and management. Chest radiographs were normal in three cases, and radiology of the bowel was misleading in five. Two developed intestinal malabsorption with megaloblastic anaemia. The finding of tubercle bacilli in the faeces presented an important diagnostic problem in one of the cases with a normal chest radiograph. All the patients required both medical and surgical treatment, and the outcome in five has been very good and relatively satisfactory in the sixth. The last case particularly illustrates the difficulty of ultimate diagnosis in some patients with granulomatous or ulcerative entero-colitis.

Tuberculous enteritis and colitis are common problems in advanced pulmonary tuberculosis. There are also some abdominal conditions, such as dyspepsia, diarrhoea, and fistula-in-ano, which are well-known modes of presentation of pulmonary tuberculosis. There are, however, two groups of patients with tuberculous entero-colitis who present more difficult diagnostic problems. First, there are those patients whose abdominal condition is secondary to unsuspected pulmonary tuberculosis and who may have extensive investigations and treatment, including surgical operation, before the diagnosis is considered. Secondly, there is a rare group of patients with tuberculous enteritis or colitis without radiological evidence of pulmonary tuberculosis. The six patients described in this paper, all of whom were seen in a general hospital, illustrate the difficulties of diagnosis and management presented by such cases.

CASE 1 P.C., a housewife aged 34, began to have attacks of vomiting in 1947. Despite two barium meals and appendicectomy no cause was found until in April 1953 an episode of severe vomiting raised the possibility of intestinal obstruction. At laparotomy 15 stenosed areas were found, each about $1 \frac{1}{2}$ in. in length, scattered throughout the jejunum and ileum. There was also a thickened area in the caecum and ascending colon. The gross appearances were those of Crohn's disease. Histological examination of a nodule from the intestinal wall showed areas of endothelioid overgrowth with giant cells and minute areas of necrosis. A gland removed from the mesentery showed areas of caseation, and Ziehl-Neelsen staining showed small numbers of acid- and alcohol-fast mycobacteria (Professor R. W. Scarff).

In July 1953 she was admitted to the Middlesex Hospital under the care of Mr. R. Vaughan Hudson.
Her only complaints were of epigastric and central abdominal pain after food, occasional vomiting, and amenorrhoea. Her weight was $7 \mathrm{st} .2 \frac{1}{2} \mathrm{lb}$. and temperature $99 \cdot 4^{\circ} \mathrm{F}$. The abdomen was slightly distended with diffuse guarding but no rigidity and no enlarged organs or abnormal masses were palpable. A radiograph of the chest showed infiltration in both upper zones and in the right midzone. Tomography showed a small cavity in the left upper zone, posteriorly. Examinations of one specimen of faeces and three specimens of gastric washings for tubercle bacilli by direct microscopy and culture were negative. The E.S.R. was $52 \mathrm{~mm}$. in one hour (Wintrobe). The $\mathrm{Hb}$ concentration was $10.2 \mathrm{~g}$. (Table I). A barium meal showed no abnormality in the oesophagus, stomach, or small bowel. The Mantoux reaction was positive at 1 in 100 (old tuberculin).

She was treated with bed rest, a high-calorie diet, and antituberculous chemotherapy, streptomycin $1 \mathrm{~g}$. intramuscularly daily and isoniazid $200 \mathrm{mg}$. by mouth. During the next two months she improved considerably. Vomiting ceased and the abdominal pain decreased in severity; she became afebrile; her weight increased by $14 \mathrm{lb}$.; the E.S.R. (Westergren) was $5 \mathrm{~mm}$. in one hour. The abdominal guarding, tenderness, and resistance, however, persisted. In January 1954 abdominal pain and vomiting returned. Although her general condition had improved, the abdominal signs had persisted and an indefinite mass was palpable in the right iliac fossa. Tubercle bacilli were not recovered from gastric washings or from the faeces. The cavity in the left lung was slightly smaller. A barium enema showed that the caecum was shrunken and deformed and the terminal ileum was dilated. A barium meal showed an apparent fistula between the duodenojejunal flexure and other loops of small gut. Multiple areas of stenosis and dilatation were seen in the small gut.

In view of the evidence of continuing intestinal obstruction, Mr. Vaughan Hudson performed a laparotomy in April 1954. Multiple strictures of the small bowel 
TABLE I

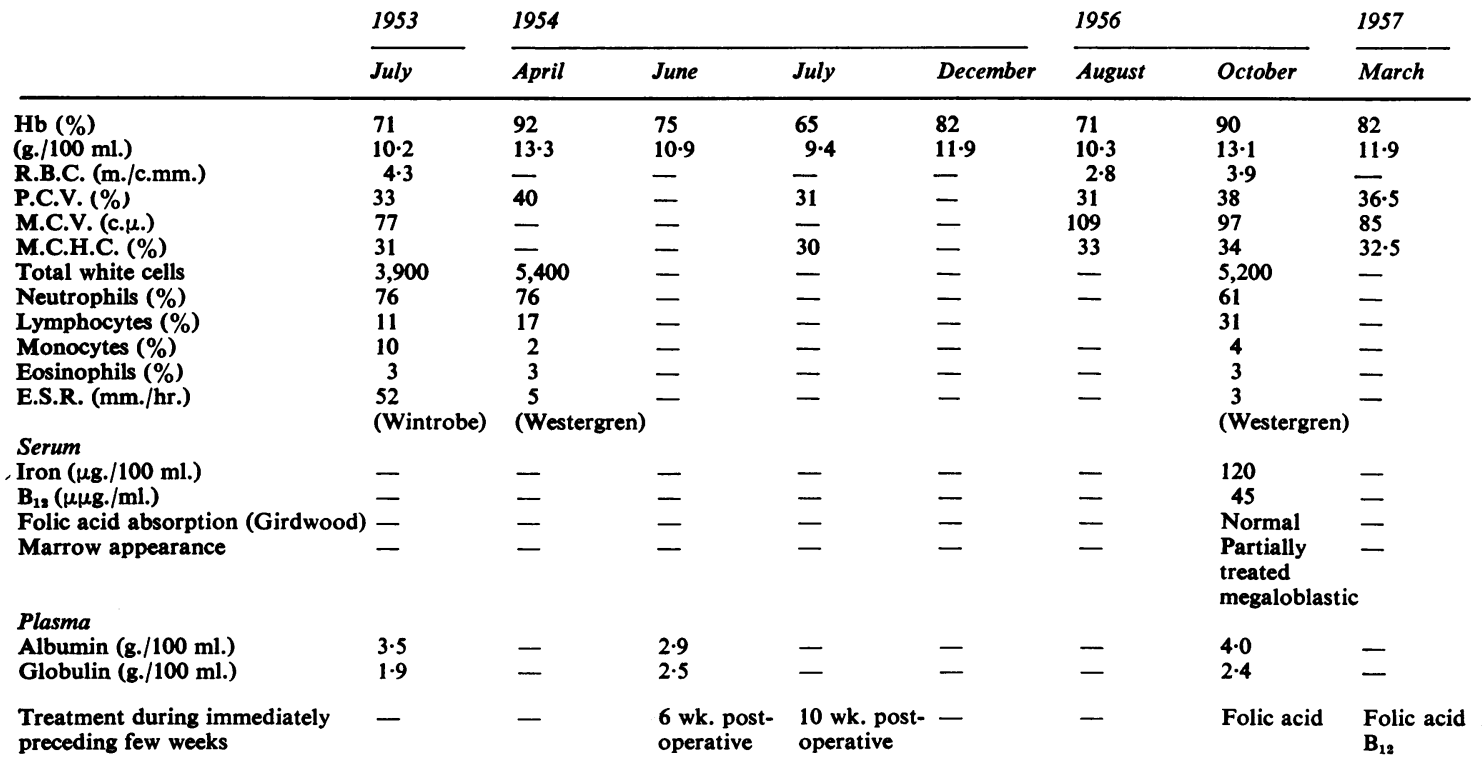

and ascending colon were found. No tubercles were visible on the peritoneum nor was there any exudate, adhesion, or fistula. The first three strictures were bypassed by a series of side-to-side anastomoses leaving the affected bowel in situ. The distal ileum was extensively diseased and was removed, together with the ascending colon. Approximately $11 \mathrm{ft}$. of small intestine was left. The resected specimen measured $4 \mathrm{ft}$. Histological examination showed multiple areas of dense fibrosis and some areas of non-specific inflammation with ulceration of the mucosa but no histological indication of active tuberculosis.

In view of the histological evidence of a fibrosing granulomatous condition it was decided to treat her with cortisone together with streptomycin in the hope of preventing further stricture formation. She was given six weeks' treatment with cortisone $100 \mathrm{mg}$. daily by mouth together with streptomycin $1 \mathrm{~g}$. intramuscularly and isoniazid $200 \mathrm{mg}$. orally. There was little clinical change directly attributable to this treatment but the steady improvement in her general condition continued, and in September 1954 she was discharged to convalescence.

In 1956 she developed a megaloblastic anaemia which responded to vitamin $B_{12}$ (Table I) and a mild peripheral neuropathy which responded to vitamin B complex. When last seen in 1961, she was very well.

CASE 2 C.H., a soldier aged 28, began in 1939 to have attacks of epigastric pain, vomiting, and diarrhoea. The appendix was removed without benefit. His symptoms recurred intermittently for the next eight years and he was investigated at four hospitals. In February 1948 a barium meal showed a filling defect in the ileo-caecal region suggestive of Crohn's disease. At laparotomy four areas of thickening of the small intestine were found between the upper jejunum and the lower ileum. Tubercles were found in the mesentery and histological examination of one showed a small area of caseation but no bacilli. A chest radiograph after this operation showed infiltration in both upper zones, more marked on the right, where there appeared to be some calcification. Tubercle bacilli were recovered from gastric washings by guinea-pig inoculation, but not from the faeces. The Mantoux reaction was positive to second strength purified protein derivative (P.P.D.). Plasma protein concentrations were normal. A barium enema showed the caecum to be high in position but no other abnormality. A further barium meal detected no lesion above the lower ileum.

In January 1949 he was transferred to the Middlesex Hospital under the care of Mr. D. H. Patey. At this time he was having infrequent attacks of abdominal pain and diarrhoea. His general condition was good, his weight normal, and he was afebrile. The abdomen was slightly tumid, there was considerable guarding with localized tenderness and an ill-defined mass to the right of the umbilicus. A radiograph of the chest showed infiltration in both upper zones and the right midzone. A barium meal detected no abnormality in the jejunum or upper ileum; the extreme terminal ileum was dilated and showed absence of peristalsis. The caecum and ascending colon were narrowed, the mucosal pattern was destroyed, and haustration lost. The blood count and E.S.R. were normal. At laparotomy in January 1949, two strictures were found, one in the upper jejunum and the other $3 \mathrm{ft}$. from the ileocaecal junction. In addition there was induration and infiltration of the caecum and ascending colon. Mesenteric glands were enlarged. The strictures were bypassed by a side-to-side anatomosis and a right hemicolectomy performed, the terminal foot of ileum being removed. Histological examination of the thickened gut walls showed granulomatous giant cell systems with overlying ulceration and acute inflammation. The lymph 
glands contained giant cell systems with small areas of caseation (Dr. J. B. Walters). Tubercle bacilli were not sought.

Ten days after operation a right pleural effusion containing straw-coloured fluid was found. A radiograph of the chest showed in addition to the pleural effusion some spread of the lesions in the upper zones as well as some basal collapse. Tubercle bacilli were cultured from a gastric washing.

The patient was treated with bed-rest and chemotherapy and later put on a sanatorium régime. Since November 1949 he has remained well. Chest radiographs showed progressive calcification of the lesions until 1953; since then they have remained stationary. His bowels are open once or twice daily and he has developed no anaemia or other evidence of malabsorption.

CASE 3 M.M., a tailor aged 35, was found in 1945 to have an abnormality in a radiograph of the chest. No further investigation was carried out. In 1946 he noticed a 'warm feeling' in the lower abdomen after urination associated with frequency. Urological investigation found nothing abnormal.

Early in 1947 he developed a feeling of pressure around the upper abdomen which was most noticeable when lying on the right side or after heavy meals and was reduced by avoiding food. In August 1947, while on board ship for South Africa, his bowels began to open three times a day but the stools were of normal character. In South Africa active pulmonary tuberculosis was diagnosed and he was treated with a sanatorium régime and pneumoperitoneum. Sputum and stomach washings and faeces did not produce tubercle bacilli on direct examination or guinea-pig inoculation. His general health improved but the abdominal symptoms persisted and in 1949 a barium meal and follow-through was said to be normal. In 1949 he returned to Britain and in 1951 was admitted to the Middlesex Hospital under the care of Dr. G. D. Hadley for investigation of the abdominal symptoms and loose stools. He had also lost some weight and vomited occasionally. He was afebrile and in good general condition. There were no abnormal signs in the chest. In the abdomen there was a firm mobile tender mass in the right iliac fossa.

$A$ radiograph of the chest showed diffuse mottling in all lung fields, particularly in the upper zones. A barium enema showed the caecum to be stenosed and suggested that there were some strictures in the terminal ileum. Examination of three samples of sputum and three of faeces for acid-fast bacilli by smear and culture were negative. The E.S.R. was $34 \mathrm{~mm}$. in one hour (Westergren) and there was a mild hypochromic anaemia of $83 \%$ $(12.0 \mathrm{~g} . / 100 \mathrm{ml}$.). The Mantoux test was positive at 1 in 1,000 .

The favoured diagnosis at this time was Crohn's disease with sarcoidosis of the lungs. This conclusion was based on the combination of a widespread infiltration in the lungs and a lesion in the bowel added to the failure to find tubercle bacilli in the sputum or faeces in 1947 and 1951.

In February 1951, Mr. C. J. B. Murray performed laparotomy. A large mass was found in the region of the caecum of which the gross appearance was suggestive of
Crohn's disease. Within the last $3 \mathrm{ft}$. of the ileum there were thickened segments of gut, which in two places formed strictures. There was a further segment $6 \mathrm{ft}$. from the ileo-caecal valve. The mesentery contained firm, enlarged glands. A right hemicolectomy was performed with a side-to-side anastomosis. The most proximal lesion was excised and the ileum anastomosed end-to-end. The post-operative course was uneventful.

In addition to the operative findings the resected gut showed mucosal ulceration at the sites of the strictures. Section of the caecal wall showed tuberculous granulation tissue with many giant cell systems but little caseation. The ileum showed small peritoneal tubercles and there were small tubercles in the glands. The appearances were those of ileocaecal tuberculosis (Dr. A. D. Thomson). A culture taken from the caecal mass grew M. tuberculosis. The organism was also isolated by guinea-pig inoculation with extracts from the caecum and mesenteric glands.

The patient's abdominal discomfort disappeared and his general condition improved. His bowels were open once or twice daily, producing loose stools.

In August 1951, tomography suggested the presence of a small cavity at the apex of the right lung. Tubercle bacilli were not recovered from the sputum. As his general condition was satisfactory and the plain radiograph showed little change, he was kept under observation without antituberculous treatment. In February 1952 he developed lupus vulgaris on the legs which cleared up with Kromayer lamp therapy.

During 1953 radiographs of the chest showed that the lesion was progressing, and in September 1953 tubercle bacilli were found in three samples of sputum on direct examination and culture. He was treated with streptomycin, P.A.S., and isoniazid in various combinations until July 1954. His sputum became negative in January 1954.

When last contacted in November 1960, he was well and his chest radiographs had been unchanged for five years. Although his bowels were only open once or twice a day, the stools tended to be loose.

CASE 4 N.B., a housewife aged 52, was well until February 1951, when she noticed undue tiredness and loss of weight. In May, there was a gradual onset of diarrhoea, with three to five slimy, offensive, occasionally pale stools each day. In June 1951 she was found to have a hypochromic anaemia (Hb 9.3 g./100 ml.), a normal white count, and an E.S.R. of $57 \mathrm{~mm}$. in one hour. A barium enema and meal showed no abnormality.

She was treated with iron by mouth without benefit and then with folic acid. Her condition, however, continued to deteriorate and in September 1951 oedema of the ankles appeared. She was admitted to the Middlesex Hospital under the care of Dr. H. L. Marriott in December 1951.

At the time of admission she weighed 5 stone (70 lb.) and, in addition to the symptoms noted above, she admitted to anorexia, exhaustion, night sweats, dyspnoea, and praecordial pain on exertion. She was found to be emaciated and to have an evening fever $\left(99.4^{\circ} \mathrm{F}\right.$.). There was generalized brown pigmentation of the skin but not of the mucous membranes, Public and axillary hair was 


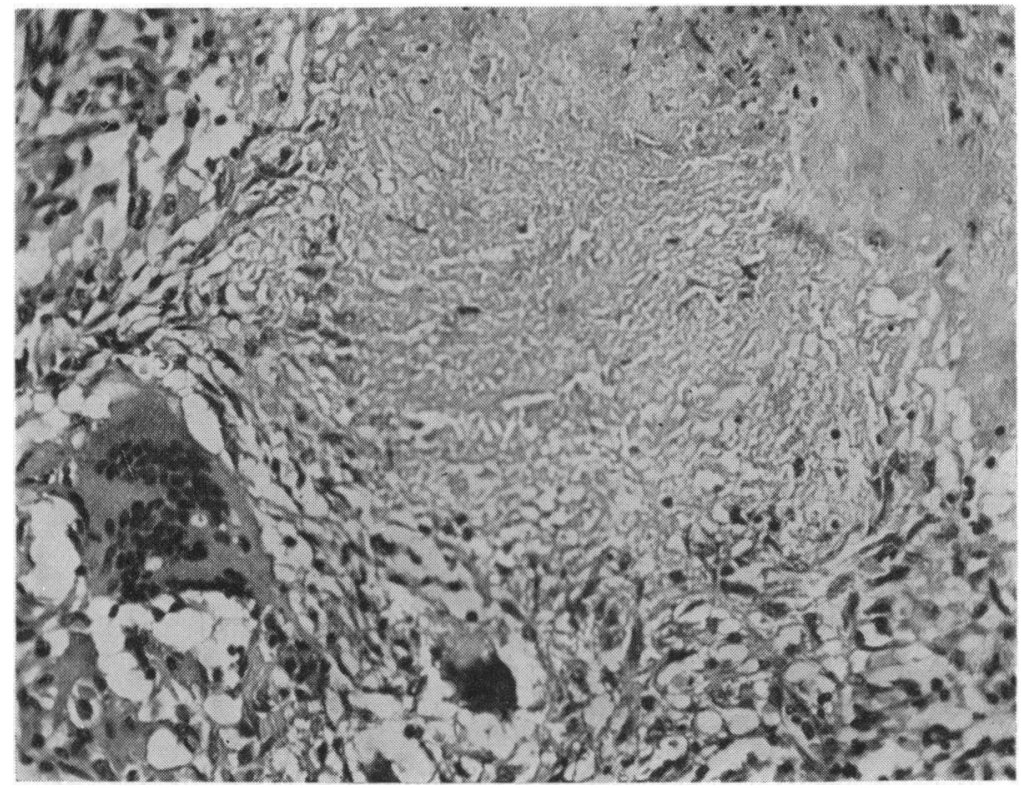

FIG 1. Section from lymph node in Case 4 showing giant cells, epitheloid cells, and extensive necrosis $(\times 230)$.

lost. The feet and legs were oedematous. The blood pressure was $130 / 70 \mathrm{~mm}$. Hg. There was no engorgement of the neck veins or clinical evidence of pulmonary congestion. No abnormality was found in the abdomen. The urine contained no excess of protein. The results of investigations performed on admission were as follows: Hb 9.4 g.; M.C.H.C. $27.5 \%$ (Table II), plasma protein concentration 5.2 g. $/ 100 \mathrm{ml}$. (albumin $2.4 \%$, globulin $2.8 \%$ ). A chest radiograph showed a calcified focus in the right lower zone and the right costophrenic angle was slightly obscured.

The immediate practical problem was to improve the malnutrition and anaemia. She was, therefore, treated with a diet of 5,000 calories and $120 \mathrm{~g}$. protein per day, with iron and full vitamin supplements by intragastric drip. Her condition improved and she was then further investigated. The faeces contained no occult blood or excess of fat. The blood urea was normal. The serum alkaline phosphatase concentration was 15.6 units per $100 \mathrm{ml}$. (the serum calcium and phosphate concentrations were not measured). Sigmoidoscopy and barium enema were normal. The stomach secreted hydrochloric acid. The bone marrow showed generalized hyperplasia; the erythroid series were mainly normoblastic but the occasional appearance of a large 'intermediate' form suggested a commencing deficiency of the vitamin B group. (She was given $30 \mathrm{mg}$. folic acid daily for about three weeks after this report.) A barium meal showed an abnormal pattern in the ileum suggestive of regional ileitis.

Two weeks after admission she developed an irregular high fever without any fresh symptoms or physical signs. There was no leucocytosis and no response to penicillin. Regional ileitis seemed the most likely diagnosis.

Laparotomy by Mr. C. J. B. Murray in January 1952 showed that the terminal $3 \mathrm{ft}$. of ileum and caecum was thickened and in places adherent to each other. The lumen was narrowed. The affected bowel was resected together with the ascending colon, and an ileo-transverse colostomy performed. The resected bowel had numerous tubercles on the serous coat and was greatly thickened with multiple strictures and large areas of mucosal ulceration. Histological examination showed that there were numerous giant cell systems with areas of caseation (Fig. 1). The appearances were those of ileo-caecal tuberculosis (Dr. A. D. Thomson).

The improvement in her general condition after operation was very satisfactory; the temperature became normal and the bowels were only open once or twice daily. She was discharged home and when seen in July 1952 she was very well and had gained 3 stone ( $42 \mathrm{lb}$.) in weight.

She remained well without any treatment until February 1954 when diarrhoea returned and she passed five or six liquid brown stools daily. She also became progressively tired and weak and in the summer of 1954 her ankles began to swell. She was re-admitted in September 1954 having lost $2 \frac{1}{2}$ stone (35 lb.) in the preceding six months.

On admission she was found to have a low-grade fever of 99 to $100^{\circ} \mathrm{F}$. There was pitting oedema of the legs but no abnormal findings in the abdomen and no signs of peripheral neuropathy. The mucous membranes were pale. A blood count showed a macrocytic anaemia with a $\mathrm{Hb}$ concentration of $6.0 \mathrm{~g} . / 100 \mathrm{ml}$. (Table II) and a few megaloblasts in the peripheral blood. The sternal bone marrow showed intense megaloblastic erythropoesis. Findings in addition to those recorded in Table II were: Serum bilirubin $2 \cdot 2 \mathrm{mg}$. per $100 \mathrm{ml}$; ; a sample of faeces contained over $50 \%$ fat; there was no occult blood in the faeces and tubercle bacilli could not be cultured from them; a fat balance showed $92 \%$ absorption on an intake of $73 \mathrm{~g}$. fat per day; most of the bones of the skeleton were abnormally radiolucent. 
TABLE II

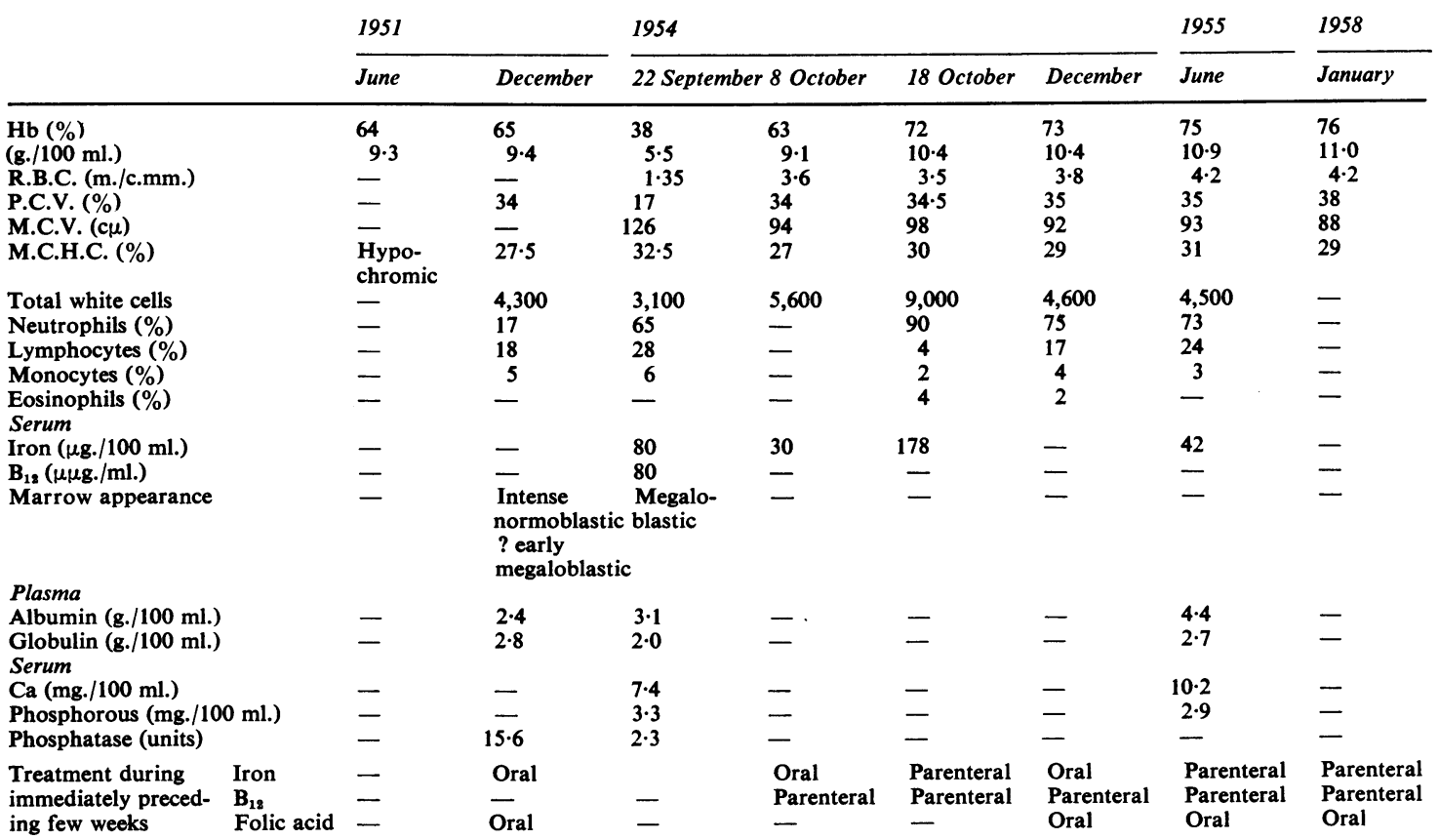

After $1 \mathrm{mg}$. of vitamin $\mathrm{B}_{12}$ intramuscularly there was a reticulocytosis of $42 \%$, the serum bilirubin level fell to $0.5 \mathrm{mg}$. per $100 \mathrm{ml}$., and the macrocytosis disappeared. The $\mathrm{Hb}$ concentration rose to $9.2 \mathrm{~g} . / 100 \mathrm{ml}$. and the M.C.V. fell to 94 c. $\mu$. The M.C.H.C., however, fell to $27 \%$ and the serum iron concentration to $30 \mathrm{mg}$. per $100 \mathrm{ml}$. in spite of the fact that she was receiving oral iron. Despite intensive treatment with parenteral iron and vitamin $B_{12}$, folic acid by mouth, and a high-protein, low-fat diet the anaemia has never been fully corrected.

In June 1955 she had gained 1 stone $(14 \mathrm{lb}$.) in weight and felt well in herself. Her bowels were open two to three times a day. Her only significant complaint was of cramp in the legs at night. There were no abnormal physical signs. Investigations showed that the plasma protein concentration and calcium concentration were now normal. A barium meal showed no abnormality in the remainder of the small intestine.

When last heard of in January 1958, she was leading a normal life. Her weight was $8 \mathrm{st} .10 \mathrm{lb}$. (130 lb.) and her bowels were acting normally.

CASE $5^{1}$ N.C., a Cypriot cook aged 29, began to have attacks of pain in the right lower abdomen in May 1959. The pain usually came on after his evening meal, and sometimes spread to the left side. The pain had no other characteristic features and, apart from loss of $14 \mathrm{lb}$. weight, was unassociated with other symptoms. He was admitted to the Middlesex Hospital under the care of Dr. G. D. Hadley in August 1959, with an apparently severe attack of pain. On examination, his general condition was good and the temperature was normal. A mobile

${ }^{1}$ This case is to be described in more detail by Ashken and Baron. firm, smooth swelling, 2 in. $\times 1$ in., was palpable in the right iliac fossa. The E.S.R. was $24 \mathrm{~mm}$. in one hour (Westergren), the plasma globulin concentration was $3.7 \mathrm{~g}$. $/ 100 \mathrm{ml}$. and the white cell count 2,900 per c.mm. (61\% polymorphs, $25 \%$ lymphocytes, and $12 \%$ monocytes). Three out of five samples of faeces contained occult blood. A chest radiograph, a barium meal (with followthrough) and barium enema on two occasions were normal. He was transferred to the care of Mr. J. H. L. Ferguson and at laparotomy the mass was found to be composed of caseous lymph nodes in the ileo-caecal mesentery. The external appearance of the bowel was normal. The terminal ileum, caecum, and proximal half of the ascending colon were resected. The specimen was found to contain two small ulcers in the ileum and ascending colon. Both these ulcers and the nodes contained numerous tubercles, giant cells, caseation, and acidalcohol fast bacilli (Dr. R. E. Cotton).

After operation, two samples of sputum were examined for tubercle bacilli; none was seen, but the culture from one of the samples was positive. Cultures of the urine were negative. $\mathrm{He}$ was treated with antituberculous chemotherapy, and a prolonged convalescence. In August 1960 , he was well and a chest radiograph was still normal.

CASE 6 N.D., a housewife aged 26, was well until April 1953, when she developed mild diarrhoea followed by lassitude and a fever of up to $104^{\circ} \mathrm{F}$. In June 1953 she was extensively investigated without a diagnosis being reached. She was treated with short courses of various antibiotics (including streptomycin) to none of which did she respond.

In August, she was transferred to the Middlesex Hospital under the care of Dr. H. L. Marriott. On 
admission her weight was 5 stone $(70 \mathrm{lb}$.), a loss of 2 stone $(28 \mathrm{lb}$.) in seven months. Additional symptoms were amenorrhoea for three months and redness of the eyes.

She was very thin, pale, and quiet but mentally alert. She had a continuous irregular fever of 100 to $102^{\circ} \mathrm{F}$. and a pulse rate of 120 to 140 . There was a mild phlyctenular conjunctivitis. The only other physical signs were in the abdomen, which was slightly distended and the spleen tip was palpable; there did not appear to be any ascites. There were no masses or areas of tenderness. In view of the possible diagnosis of tuberculous peritonitis, paracentesis of the abdomen was attempted but no fluid was found.

She was extensively investigated for the usual causes of pyrexia without a diagnosis being reached until the faeces were specially examined for tubercle bacilli which were found on direct examination of two successive stools. The bacilli were cultured from one of these stools, and subsequently identified as being of human type.

The results of other relevant investigations performed at this time were as follows. A chest radiograph was normal. $\mathrm{Hb}$ concentration was $7.2 \mathrm{~g} . / 100 \mathrm{ml}$., red cells 3.1 m. per c.mm., M.C.V. 80 c. $\mu$., M.C.H.C. $29 \%$, white cells 7,500 per c.mm. (neutrophils $63 \%$, lymphocytes $26 \%$, monocytes $10 \%)$. A Mantoux test (1 in 1,000 O.T.) was positive; gastric washings contained no tubercle bacilli.

She was thought to be suffering either from miliary tuberculosis or tuberculous enteritis. Treatment with streptomycin and isoniazid was begun and she also received extensive measures, including high-calorie supplementary feeds and blood transfusion designed to improve her general condition.

At the end of October her condition was sufficiently improved to permit further investigation. A barium enema examination was technically difficult but revealed no abnormality in the colon or terminal few inches of the ileum. The appearances at a barium meal were normal in the upper jejunum but in the lower jejunum and upper ileum the mucosal pattern had coarsened and the barium had become clumped. A stricture appeared to be present in this region. The lower ileum was not satisfactorily visualized.

These findings suggested that there might be a localized tuberculous ileitis.

At laparotomy by Mr. C. J. B. Murray in November 1953, the small intestine was found to be normal; the caecum was thickened and the serous coat was studded with tubercles; there were enlarged glands in the mesentery. There was a similar but smaller area of disease in the transverse colon near the splenic flexure. A right hemicolectomy was performed and an ileo-transverse colostomy created, leaving the smaller diseased area in situ.

The resected specimen showed multiple shallow serpiginous ulcers with polypoid overgrowth and some fibrosis of the wall of the bowel. On microscopy the ulcers were found to have perforated the mucosa and in places the muscle of the colon. There was infiltration with round cells and occasional giant cells. The appearances were considered to be compatible with treated tuberculosis (see later).
The patient's immediate post-operative course was satisfactory and her subsequent progress was excellent. She became afebrile within one week, and in six weeks she regained her normal weight of 7 stone (a gain of $22 \mathrm{lb}$.). Her bowel action was normal and the blood haemoglobin concentration was $13.6 \mathrm{~g} . / 100 \mathrm{ml}$. However, she still had a tachycardia when out of bed, the stools contained occult blood, and the E.S.R. was 15 to $20 \mathrm{~mm}$. in one hour (Westergren). She was therefore given antituberculous chemotherapy for a further two months.

She remained well until July 1954, when she had a recurrence of diarrhoea passing four or five bloody stools each day, fever, loss of weight, and abdominal pain. She was re-admitted to the Middlesex Hospital under the care of Dr. F. H. Scadding in September 1954. On admission her weight was 7 stone ( $98 \mathrm{lb}$.); she had a regular swinging fever of 99 to $102^{\circ} \mathrm{F}$. In the left hypochondrium there was tenderness, associated with guarding, and an ill-defined mass. The $\mathrm{Hb}$ concentration on admission was 10.9 g./100 ml. with a normal M.C.V. and M.C.H.C.; the white cell count was normal. Tubercle bacilli were not found in the facees (five samples) either on direct examination or on culture. A chest radiograph was normal.

It appeared probable that the tuberculosis at the splenic flexure had become active again. Treatment with streptomycin, isoniazid, and full supportive measures was begun. There was, however, little evidence of response. Throughout the next six weeks her fever continued unchanged; she lost $21 \mathrm{lb}$. in weight and the $\mathrm{Hb}$ concentration repeatedly fell to less than $10 \mathrm{~g} . / 100 \mathrm{ml}$. in spite of blood transfusions. The diarrhoea diminished slightly but the stools continued to be watery and to contain fresh blood.

Sigmoidoscopy showed that the rectum was relatively normal so Mr. C. J. B. Murray again performed a laparotomy. There was gross inflammation of the colon beyond the anastomosis, most marked at the splenic flexure, with a similar smaller area of disease at the recto-sigmoid junction. The colon was removed and an ileo-rectal side-to-side anastomosis formed. The histology of the resected bowel was identical with that removed at the first operation.

The patient's immediate postoperative course was satisfactory and four days later she was afebrile. She subsequently improved steadily with bed rest and continued antituberculous chemotherapy. Three months after operation, she had gained 1 stone in weight. Her bowels were open three or four times daily, with an unformed but not watery stool containing no fresh or occult blood. The $\mathrm{Hb}$ concentration was $12 \cdot 3 \mathrm{~g}$. $/ 100 \mathrm{ml}$. and E.S.R. (Westergren) $8 \mathrm{~mm}$. in one hour. A fat balance showed a faecal loss of $5.8 \mathrm{~g}$. per day on an intake of $70 \mathrm{~g}$. fat.

The improvement continued after discharge and in May 1955 she had returned to her normal weight of 7 stone (98 lb.). Her bowel action was unchanged. She was given oral treatment with isoniazid and P.A.S. until November 1955 and she remained well for three years and had a baby in July 1958. In February 1959, diarrhoea recurred and the patient lost weight and experienced increasing muscular weakness. On re-admission in April 1959, her weight was $5 \frac{1}{2}$ stone $(77 \mathrm{lb}$.), pulse rate 120 , blood pressure $85 / 60 \mathrm{~mm}$. $\mathrm{Hg}$, and she was very weak. There were no 
localized physical signs. She was found to have mild anaemia (Hb 12.9 g.) mild hypokalaemia and hyponatraemia (serum potassium $3.2 \mathrm{mEq} . / \mathrm{l}$. and sodium $132 \mathrm{mEq}$./1.). The blood urea was $40 \mathrm{mg}$. $/ 100 \mathrm{ml}$. and the daily 17 -ketosteroid excretion was $1.5 \mathrm{mg}$. These findings were attributed to her poor general condition and the diarrhoea. A barium enema and meal suggested the presence of ulcers in the terminal ileum and a developing stricture at the ileo-rectal anastomosis. No tubercle bacilli were recovered from three samples of faeces by direct examination or culture. In view of the previous history and the radiological findings, she was treated with streptomycin and isoniazid as well as many supportive measures including corticosteroids. In spite of these, her condition gravely deteriorated, and she had episodes of hypothermia, hypotension, and unexplained obstructive jaundice. Dr. Avery Jones suggested that regional enteritis was a more likely diagnosis than tuberculous enteritis. Sigmoidoscopy showed a friable granular mucosa resembling ulcerative colitis. Antituberculous chemotherapy was stopped. She improved and in July 1959 left hospital still taking prednisone by mouth. When last seen in July 1960, she was very well, her bowels were open five or six times a day, and her weight was $95 \mathrm{lb}$.

The histology of the bowel resected in 1953 and 1954 was reviewed and regional enteritis was preferred to the original diagnosis of treated tuberculosis because there was no convincing evidence of caseation, the giant cells were too variable in type, many of them being of the foreign body variety, and the granulomatous process was too vascular (Dr. A. D. Thomson).

The diagnosis is further discussed below.

\section{DISCUSSION}

These cases illustrate first the variability of the clinical picture, secondly the difficulties in diagnosis, and thirdly the good results of modern treatment.

It must be admitted in retrospect that only in Case 6 was the clinical picture so unusual that the full diagnosis of the site as well as of the nature of the condition could not have been suspected.

In the first and second cases, the pulmonary lesions were probably of long standing, and an earlier chest radiograph might have suggested the diagnosis. In the third case the long history and very diffuse pulmonary infiltration combined with failure to find tubercle bacilli led to a diagnosis of sarcoidosis being preferred to that of tuberculosis.

Kogan and Janowitz (1956) have described seven cases of intestinal tuberculosis which were operated on before the diagnosis was suspected, and in three of these chests radiographs after operation showed pulmonary tuberculosis.

Cases 4,5 , and 6 , on the other hand, raise the general problem of diagnosing intestinal tuberculosis in the presence of a normal chest radiograph. An examination of the literature suggests that in adults this is an uncommon problem. Unfortunately, most of the early literature on this subject was before the recognition of regional ileitis, and the diagnosis of primary hyperplastic tuberculosis in such series must be suspect. However, the extensive review of Brown and Sampson (1930) shows that, even before regional ileitis was described as a separate entity, the problem was uncommon. Following the description of regional ileitis, American writers (Bockus, 1944; Crohn and Yarnis, 1940) came to regard 'primary' tuberculous entero-colitis as an extreme rarity. This view must not be allowed to prevent tuberculosis being considered clinically in patients with normal chest radiographs. Two of seven cases in a series based on the years 1936-56 described by Kogan and Janowitz had negative chest radiographs, and nine of 58 cases of intestinal tuberculosis seen at the Mayo Clinic between 1921 and 1946 (Hoon, Dockerty, and Pemberton, 1950) had no evidence of extra-enteric tuberculosis. Paustian and Bockus (1959) only managed to find eight reports recording 25 cases of tuberculous enteritis in the absence of active pulmonary disease in the American literature since 1940. Anand (1956) has described from India 50 cases of hyperplastic ileo-caecal tuberculosis, 39 of which had no pulmonary lesion (apparently as judged by radiographs and sputum examination). Tubercle bacilli of human type were isolated from 25 of these 39 cases.

To these must be added my Cases 4 and 5 (and possibly Case 6). Obviously, these reports raise the pathological problem of the nature of Crohn's disease and its relation to tuberculosis. This consideration is outside the scope of this paper, but it is important to consider the possibility of tuberculosis in individual cases because of the therapeutic implications.

The confirmation of the diagnosis of tuberculosis in patients with normal chest radiographs presents a difficult problem. It would appear worthwhile to examine the faeces for tubercle bacilli. It is ironical that, in the present series, they were only found in Case 6 in which the diagnosis remains doubtful. The irony is heightened by the fact that the finding of tubercle bacilli in the stools was the most persuasive factor behind the decision to operate on such an extremely ill patient, and may therefore have saved her life.

The chief method of diagnosis in intestinal tuberculosis, of course, must be by radiology. Experience with Cases 1, 2, 3, 5, and 6 was in this connexion unfortunate, but illustrates the difficulties of the method. In Kogan and Janowitz's series, there were five patients in whom adequate radiological and surgical examination of the bowel permit comparison. In four of these the radiological findings, while showing some abnormality, seriously underestimated or misinterpreted the true situation. The 
one patient in whom the radiological findings were accurate was studied by the direct instillation of a small amount of barium into the duodenum.

There are three ways in which radiology may be misleading; first by failing to find any abnormality in the presence of fairly extensive disease; secondly, by finding abnormalities which are not due to disease; and thirdly, by misinterpretation of the nature of those lesions which are detected. Radiologists are much more aware of the difficulties than are clinicians, and would be greatly helped if the latter gave them clear indications when granulomatous lesions are suspected, so that they can use special techniques.

The number of cases is too small and dissimilar to justify general conclusions about treatment, but the course of the illness in Case I suggests that chemotherapy was of benefit. Surgery was not radical in this patient, and much of the credit for the eventual outcome may be attributable to chemotherapy. When the granulomatous process is very marked, as in Case 1, the combined use of steroids and antituberculous chemotherapy may be worthy of trial.

The development of a serious malabsorption syndrome without significant clinical evidence of extensive tuberculous enteritis in Case 4 is more surprising than its recurrence after extensive resection in this patient or its appearance in Case 1. The presence of megaloblastic anaemia as part of the malabsorption syndrome is probably only a reflection of the duration of the condition; in neither case did it appear to be due to a blind loop.

Case 6 remains somewhat of a mystery. When this series of patients was collected in 1958, she appeared to be an example of primary tuberculous colitis, a condition which does not seem to have been described. It now seems possible that she has an unusual form of regional enteritis, verging on ulcerative colitis. She has been retained in this series for four reasons; first, she illustrates the difficulty of making a certain diagnosis in this group of conditions, even when histology is available; secondly, she illustrates the limitations of routine radiological techniques in this type of case; thirdly, she presents the problem of interpreting the finding of tubercle bacilli in the faeces. The explanation of their presence is very difficult, because tubercle bacilli only appear in the faeces in sufficient numbers to be seen on direct examination either in open cavitating pulmonary tuberculosis or in ulcerative tuberculosis of the gut. Their presence as contaminants in sufficient numbers for detection is unknown (O'Grady and Thompson, personal communication). Finally, therefore, we have the fourth reason for retaining this case in the series; she may, in fact have had tuberculous colitis. The conflict between the histological and bacteriological evidence may be resolved by reference to the experience of Wig, Singh, Chitkara, and Gupta (1954), who described four patients in whom tuberculous enteritis was diagnosed on tissue removed at operation (in one case, tubercle bacilli were recovered). At second operations after chemotherapy, only the changes of a non-specific granuloma were found. Taylor (1945) also described the disappearance of caseation necrosis and tubercle bacilli in the later stages of tuberculous enteritis.

I am grateful to all the physicians and surgeons, both at the Middlesex and other hospitals, for permission to describe these patients and for their advice in the preparation of these histories. I am also grateful to all the pathologists and radiologists for discussing their reports with me. Dr. M. P. Spence kindly read the manuscript. The photomicrographs were prepared by Drs. R. E. Cotton, A. C. Thackray, and A. D. Thomson.

\section{REFERENCES}

Anand, S. S. (1956). Hypertrophic ileo-caecal tuberculosis in India with a record of fifty hemicolectomies. Ann. roy. Coll. Surg. Engl., 19, 205-222.

Bockus, H. L. (1944). Gastro-enterology, Vol. 2, p. 197. Saunders, Philadelphia.

Brown, L., and Sampson, H. L. (1930). Intestinal Tuberculosis: Its Importance, Diagnosis and Treatment, 2nd ed. Lea and Febiger, Philadelphia.

Crohn, B. B., and Yarnis, H. (1940). Primary ileocecal tuberculosis. N.Y.St. J. Med., 40, 158-166.

Hoon, J. R., Dockerty, M. B., and Pemberton, J. de J. (1950). Ileocecal tuberculosis including a comparison of this disease with nonspecific regional enterocolitis and noncaseous tuberculated enterocolitis. Int. Abstr. Surg., 91, 417-440.

Kogan, E., and Janowitz, H. D. (1956). Intestinal tuberculosis: difficulties in diagnosis in the absence of florid pulmonary involvement. J. Mt Sinai Hosp., 23, 597-615.

Paustian, F. F., and Bockus, H. L. (1959). So-called primary ulcerohypertrophic ileocecal tuberculosis. Amer.J. Med., 27, 509-518.

Taylor, A. W. (1945). Chronic hypertrophic ileocaecal tuberculosis, and its relation to regional ileitis (Crohn's disease). Brit. $J$. Surg., 33, 178-181.

Wig, K. L., Singh, M. M., Chitkara, N. L., and Gupta, S. P. (1954). Observations on histological changes in cases of hyperplastic intestinal tuberculosis after treatment. Indian J. Tuberc., 1, 151-160. 